\title{
Restarting cataract surgery during the COVID-19 pandemic; a prospective study analysing 30 day outcomes after elective cataract surgery in the United Kingdom
}

Francis Carr ${ }^{*}$, Paras Agarwal, Harmehak Narula, Tiran S. Keragala, Samer Elshikh Hassan Awwad, Ahmed Roble and Vinod Gangwani

\begin{abstract}
Background: Cataract is a significant cause of preventable blindness in the United Kingdom and worldwide. Prior to the COVID-19 pandemic, cataract surgery was the most commonly performed operation by the National Health Service in the United Kingdom. The aim of this study is to evaluate the safety of elective cataract surgery performed in the United Kingdom in a COVID-19 free hospital during the COVID-19 pandemic.

Methods: Single centre prospective observational cohort study of consecutive patients undergoing elective cataract surgery in the United Kingdom over a 3 month period from May to August 2020. Electronic medical records were reviewed and patients were contacted at 30 days post-operatively. Data collection included symptoms suggestive of COVID-19 infection, hospital admission, mortality, intra-operative and post-operative surgical complications.

Results: A total of 649 elective cataract surgeries were performed. Two patients (0.3\%) developed worsening dyspnoea during the 30 day post-operative period, but tested negative for COVID-19 infection. Three patients (0.5\%) were hospitalised, unrelated to COVID-19 infection, of which one patient (0.2\%) passed. Four patients (0.6\%) suffered posterior capsular rupture. 601 (93.2\%) had no post-operative complications.
\end{abstract}

Conclusion: This study demonstrates a safe model for the resumption of elective cataract surgery during the COVID-19 pandemic, providing strict infection control measures are in place.

Keywords: Cataract, Cataract surgery, Phacoemulsification, COVID-19, Coronavirus

* Correspondence: Francis.Carr@nhs.net

Ophthalmology Department, Ashford \& St Peter's Hospitals NHS Foundation

Trust, Ashford, UK

(c) The Author(s). 2021 Open Access This article is licensed under a Creative Commons Attribution 4.0 International License, which permits use, sharing, adaptation, distribution and reproduction in any medium or format, as long as you give appropriate credit to the original author(s) and the source, provide a link to the Creative Commons licence, and indicate if changes were made. The images or other third party material in this article are included in the article's Creative Commons licence, unless indicated otherwise in a credit line to the material. If material is not included in the article's Creative Commons licence and your intended use is not permitted by statutory regulation or exceeds the permitted use, you will need to obtain permission directly from the copyright holder. To view a copy of this licence, visit http://creativecommons.org/licenses/by/4.0/ The Creative Commons Public Domain Dedication waiver (http://creativecommons.org/publicdomain/zero/1.0/) applies to the data made available in this article, unless otherwise stated in a credit line to the data. 


\section{Introduction}

Prior to the coronavirus disease 2019 (COVID-19) pandemic, cataract surgery was the most commonly performed operation in the United Kingdom's National Health Service (NHS) [1]. The World Health Organisation (WHO) estimates cataract is the second largest cause of treatable visual impairment globally [2]. In the United Kingdom, an estimated 380,000 people are living with sight loss due to cataract [3].

COVID-19 was declared a Public Health Emergency of International Concern by WHO on 30 January 2020 [4]. Since its outbreak, it has brought significant harm and challenges to over 200 countries and regions around the world. To date, there have been over 50 million confirmed cases of COVID-19 and over one million deaths reported to WHO [5].

In response to rising COVID-19 cases in the United Kingdom, NHS England and NHS Improvement announced COVID-19 a Level 4 National Incident on 17 March 2020 [6]. NHS trusts were instructed to suspend elective services to minimise virus transmission and augment capacity to cope with a surge in COVID-19 infections and its demand on hospital resources. On 28 March 2020, the Royal College of Ophthalmologists (RCOphth) recommended eye units postpone all elective eye operations and non-urgent outpatient clinics [7]. Understandably, cataract surgery faced significant disruption. On 16 April 2020, the RCOphth issued guidance regarding the prospective resumption of cataract surgery in order to ensure a safe environment for patients and staff, acknowledging the necessity to address the resultant large backlog in cases and provide patients with a timely service [8]. Failure to do so would compromise the quality of life of many patients [9].

Currently, there is no available data investigating safety following the resumption of cataract surgery during the COVID-19 pandemic. This prospective study provides data regarding patients undergoing elective cataract surgery performed in a COVID-19 free hospital in the United Kingdom.

\section{Methods}

This single centre, prospective, observational cohort study analysed patients who had elective cataract surgery, under local and general anaesthesia, at Ashford Hospital (part of the Ashford and St Peter's NHS Foundation Trust) in the United Kingdom. Ashford Hospital has been a COVID-19 free hospital throughout the COVID-19 pandemic, as defined by no inpatients with suspected or proven COVID-19 infection. Consecutive patients undergoing cataract surgery over a 3 month period during the COVID-19 pandemic, from 19 May 2020 (when cataract services resumed at the aforementioned hospital) to 18 August 2020, were included. Data collection was routine, with no resultant alteration in clinical practice. The Institutional Review Board at Ashford and St Peter's NHS Foundation Trust reviewed and approved the study protocol (TASCCOPHTH (202005)). All study conduct adhered to the Declaration of Helsinki for the use of human participants in biomedical research.

After full discussion of the potential benefits and risks of undergoing cataract surgery during the COVID-19 pandemic, over the phone, patients were offered cataract surgery on the basis of waiting list time and clinical urgency. Patients were not excluded from selection due to age or comorbidities. All patients signed a consent form acknowledging the potential risk of contracting COVID19 infection during their visit to the hospital.

All patients were screened with a COVID-19 nasopharyngeal swab test (testing for severe acute respiratory syndrome coronavirus 2 RNA) $72 \mathrm{~h}$ before the day of surgery, and were allowed to proceed providing it was negative. The testing was performed at a drive-through test site, with the patient required to remain in their car during the testing process. Following national guidance, patients were initially instructed to self-isolate for 14 days before the operation for surgery. A change in National Institute for Health and Care Excellence (NICE) recommendations [10] resulted in a reduction in the self-isolation period to 3 days following their preoperative COVID-19 swab, which was implemented 5 August 2020 onwards. Patients were not instructed to isolate following their operation.

Patients had staggered admission times to strictly maintain a two metre distance between patients, with five patients listed for each morning and afternoon list. No accompanying persons were allowed into the hospital with the patient, unless required due to cognitive impairment. On entering the hospital, temperature was monitored using a non-contact handheld cutaneous infrared thermometer and the patients were screened for symptoms suggestive of COVID-19 infection. Patients with symptoms or a temperature $>37.8$ degrees Celsius precluded entry into the hospital. Patients were instructed to don a new sterile surgical mask whilst they were in hospital, which was removed temporarily during the operation, when a sterile drape was placed over the head. The mask was replaced immediately following completion of the operation and placement of the protective eye shield.

Local policy was implemented to minimise potential risk of spreading infection. Each team member wore appropriate personal protective equipment, including surgical masks, aprons and gloves whilst operating and coming into contact with patients. No changes were made to personnel performing cataract surgery, with trainee lists continuing as normal, although the majority 
of operations were performed by consultant ophthalmologists. Operating surgeons did not necessarily spend all day in theatre, with some attending clinic in the morning, followed by theatre in the afternoon, and vice-versa.

Ophthalmology theatres were not separate from theatres used by other specialities. No changes were made to theatre airflow conditions (laminar flow). For patients requiring general anaesthesia, intubation and extubation occurred in theatre, with a minimum of 7 min before other staff could enter, to reduce the risk of aerosol transmission.

Routine post-operative care comprised of two phone calls from trained ophthalmology nursing staff at postoperative days one and 14, followed by an optician review at 6 weeks. Routine face-to-face appointments could be arranged at the discretion of the operating surgeon. Patients were issued with a $24 \mathrm{~h}$ telephone number to contact the ophthalmology department (within office hours) or on-call ophthalmologist (outside of office hours) if post-operative complications arose and they required a face-to-face review. Similarly, if nursing staff phone calls identified a post-operative issue requiring a face-to-face review, then that appointment could be arranged at their discretion.

Data for the study was collected 30 days following cataract surgery. Electronic health records were reviewed and patients were contacted via telephone. If patients were unable to communicate via telephone then data was collected via their main carer.

The primary outcome of the study was swab proven COVID-19 infection within the 30 day post-operative period. Secondary outcomes included COVID-19 symptoms (high temperature, cough, dyspnoea, coryzal symptoms, anosmia and systemic upset), hospitalisation, ICU admission and mortality.

Intra-operative complications were recorded, by reviewing the operation report. Post-operative follow-up was analysed, including arranged follow-up (whether via telephone or face-to-face), complications arising within the 30 day period, the number of reviews within the 30 day period and the number of subsequent operations.

Patient experience data was collected. This encompassed a questionnaire over the telephone, using a five point Likert scale. Each question was analysed independently.

Statistical analysis was performed using SPSS Statistics Version 26 (IBM, USA). Quantitative endpoints are presented as mean \pm standard deviation. Qualitative endpoints are presented as numbers and the percentage of each modality.

\section{Results}

The patient demographics are demonstrated in Table 1. All patients were able to be contacted via telephone, alongside a review of their electronic medical records.
Table 1 Demographic data

\begin{tabular}{|c|c|}
\hline \multicolumn{2}{|l|}{ Eye } \\
\hline Right & $322(49.6 \%)$ \\
\hline Left & $327(50.4 \%)$ \\
\hline First & $353(54.3 \%)$ \\
\hline Second & $296(45.6 \%)$ \\
\hline \multicolumn{2}{|l|}{ Anaesthesia } \\
\hline Local & $646(99.5 \%)$ \\
\hline General & $3(0.5 \%)$ \\
\hline \multicolumn{2}{|l|}{ Age (years) } \\
\hline Mean (SD) & $\begin{array}{l}73.7(9.61), \min 21 \\
\max 97\end{array}$ \\
\hline \multicolumn{2}{|l|}{ Age group } \\
\hline$\leq 45$ & $2(0.3 \%)$ \\
\hline $46-64$ & $120(18.5 \%)$ \\
\hline $65-74$ & $198(30.5 \%)$ \\
\hline $75-84$ & $261(40.2)$ \\
\hline$\geq 85$ & $68(10.5 \%)$ \\
\hline \multicolumn{2}{|l|}{ Sex } \\
\hline Male & $272(42.0 \%)$ \\
\hline Female & $377(58.0 \%)$ \\
\hline \multicolumn{2}{|l|}{ Ethnicity } \\
\hline Non-BAME & 469 (72.3\%) \\
\hline BAME & $180(27.7 \%)$ \\
\hline \multicolumn{2}{|l|}{ Body Mass Index $\left(\mathrm{kg} / \mathrm{m}^{2}\right)$} \\
\hline Mean (SD) & $\begin{array}{l}25.7(4.60), \min 14.7 \\
\max 58.3\end{array}$ \\
\hline$<18.5$ & $14(2.2 \%)$ \\
\hline $18.5-24.9$ & $317(48.8 \%)$ \\
\hline $25.0-34.9$ & $297(45.8 \%)$ \\
\hline $35.0-44.9$ & $18(2.8 \%)$ \\
\hline$\geq 45$ & $3(0.5 \%)$ \\
\hline \multicolumn{2}{|l|}{ Comorbidities } \\
\hline Active malignancy & $31(4.8 \%)$ \\
\hline $\begin{array}{l}\text { Cardiac disease (including arrhythmias, } \\
\text { ischaemic heart disease and cardiac failure) }\end{array}$ & $158(24.3 \%)$ \\
\hline Cerebrovascular disease & $30(4.6 \%)$ \\
\hline Chronic kidney disease & $32(4.9 \%)$ \\
\hline $\begin{array}{l}\text { Chronic lung disease (including asthma and } \\
\text { chronic obstructive pulmonary disease) }\end{array}$ & $101(15.6 \%)$ \\
\hline Diabetes mellitus & $173(26.7 \%)$ \\
\hline Hypertension & $344(53.0 \%)$ \\
\hline $\begin{array}{l}\text { Taking immunosuppressive medication } \\
\text { (including prednisolone) }\end{array}$ & $18(2.8 \%)$ \\
\hline
\end{tabular}

Over the 3 month period, from 19 May 2020 to 18 August 2020, 649 elective cataract surgeries were performed on 631 patients, with 18 patients having both eyes operated on within the study timeframe. 322 
(49.6\%) of the operations were on the right eye, 327 $(50.4 \%)$ were on the left eye, $353(54.3 \%)$ were the first eye, 296 (45.6\%) were the second eye. The mean age $( \pm$ SD) was 73.7 years $\pm 9.61,272$ (42.0\%) were male eyes, 377 (58.0\%) were female eyes. 180 (27.7\%) patients identified as Black, Asian and minority ethnic (BAME). With regards to comorbidities, hypertension was the most common, 344 (53.0\%), followed by diabetes mellitus $(173,26.7 \%)$ and cardiac disease (158, 24.3\%).

Regarding anaesthesia, nearly all operations (646, 99.5\%) were performed under local anaesthesia. 638 (98.3\%) had no intraoperative complications (Table 2). The most common intraoperative complication was posterior capsular rupture $(4,0.6 \%)$, followed by zonular dialysis (3, 0.5\%). Most follow-up was performed over the phone, with 44 operations $(6.8 \%)$ requiring a face-toface review (Table 3), either due to an intra-operative complication, or an associated procedure performed during the operation, such as a dexamethasone implant, iStent implant or toric lens insertion.

Forty patients (6.2\%) required an unscheduled face-toface review in the 30 day post-operative period. Of those, $5(12.5 \%)$ reviews were on the same day as the patient reporting their symptoms, $14(35 \%)$ were within 1-3 days, $16(40 \%)$ were within 4-7 days and $5(12.5 \%)$ were within 8-14 days. $20(50 \%)$ strongly disagreed with the statement 'it was difficult to arrange an unscheduled face-to-face appointment', 4 (10\%) strongly agreed.

84 (12.9\%) patients required a face-to-face review in clinic within 30 days of their operation, including both scheduled and unscheduled. 60 (9.2\%) required one review in total, one patient $(0.2 \%)$ required five reviews.

48 (7.4\%) post-operative complications were identified within 30 days, the most common being newly recognised floaters (11, 1.7\%), followed by corneal oedema and ocular surface disorders, both in 8 eyes (1.2\%). Three patients $(0.5 \%)$ required further surgery within the 30 day period, two $(0.3 \%)$ of which were vitrectomy and secondary intraocular lens (IOL) insertion, the other $(0.2 \%)$ being an anterior chamber washout due to retained lens matter.

Ninety-six patients $(14.8 \%)$ continued shielding following the operation (Table 4). Two patients $(0.3 \%)$ reported having suffered COVID-19 symptoms within the 30 day

Table 2 Intraoperative complications

\begin{tabular}{ll}
\hline Intraoperative complications & \\
\hline None & $638(98.3 \%)$ \\
Posterior capsular rupture & $4(0.6 \%)$ \\
Zonular dialysis but not vitreous prolapse & $3(0.5 \%)$ \\
Anterior capsular tear out & $2(0.3 \%)$ \\
Descemet's tear & $1(0.2 \%)$ \\
Dropped nucleus & $1(0.2 \%)$ \\
\hline
\end{tabular}

post-operative period, both of which were dyspnoea and both of which tested negative for COVID-19. Of the entire cohort, three patients (0.5\%) had COVID-19 nasopharyngeal swabs performed, of which all were negative. Those three patients had their swabs performed during admission to hospital. One patient was admitted for investigation of vertigo, another for management of an exacerbation of combined cardiac and renal failure and the last patient due to an exacerbation of cardiac failure secondary to aortic valve stenosis (who sadly passed within the 30 day post-operative period, his next-of-kin supplied data). The medical teams deemed all three presentations unrelated to COVID-19 infection.

Patient experience data was collected from all patients (Table 5), barring the one mortality (648 in total). 507 (78.2\%) strongly agreed with the statement that they were "happy with their decision to proceed with cataract surgery', 2 patients $(0.3 \%)$ strongly disagreed, both of which had suffered complications related to their surgery. The majority of patients either disagreed (123, $19.0 \%)$ or strongly disagreed $(366,56.5 \%)$ with the statement that they were concerned they may have caught COVID-19 due to attending hospital for the cataract surgery. The vast majority strongly agreed $(578,89.2 \%)$ or agreed $(68(10.5 \%)$ with the statement that there were adequate infection control measures in hospital to prevent transmission of COVID-19.

\section{Discussion}

As far as we are aware, this is the first study demonstrating prospectively collected data on the safety of elective cataract surgery performed during the current COVID19 pandemic. Due to the multitude of cancelled elective operations, the backlog has been rapidly accumulating. Numerous recommendations have been provided in order to safely resume elective services $[8,10-12]$. We provide evidence of a safe model for the resumption of elective cataract surgery in a COVID-19 era.

None of our cohort had swab proven COVID-19 infection in the 30 day post-operative period. Regarding symptoms, very few patients reported COVID-19 related symptoms following the operation. Patient recollection is fallible, although we believe that patients would be particularly mindful of them in current times. If significant enough to warrant presentation to hospital, then we were able to monitor for this independently by reviewing electronic medical records, although this would not detect patients who had travelled out-of-area and subsequently became unwell. Patients may be reticent to disclose symptoms due to the concern that they may subsequently be asked to self-isolate or it may in some way affect their post-operative care (although the contrary was stated during data collection). Our study was the unable to detect asymptomatic infection rates in 
Table 3 Follow-up and post-operative complications

Planned post-operative follow-up
Phone call alone
Face-to-face appointment (e.g. toric lens,
dexamethasone implant, iStent, intra-op
complication)
Post-operative complications within
30 day period
None
Floaters/uncomplicated posterior vitreous
detachment
Corneal oedema
Ocular surface disorder
Blurred vision but no abnormality detected
Raised intraocular pressure
Macular oedema
Dysphotopsia
Central retinal vein occlusion
Posterior capsular opacification
Refractive surprise
Retained lens matter
Face-to-face appointment within
appointments)
No
Yes

$565(87.1 \%)$

$84(12.9 \%)$

Planned: 44 (6.8\%)

Unplanned: 40 (6.2\%)

Number of

appointments

1: $60(9.2 \%)$

2: $9(1.4 \%)$

3: $10(1.5 \%)$

4: $4(0.6 \%)$

5: $1(0.2 \%)$

Further operation within 30 days post-op

Duration between symptoms and being reviewed in clinic

$$
\begin{aligned}
& \text { Average (SD) } \\
& \text { Range } \\
& 0 \text { days } \\
& 1-3 \text { days } \\
& 4-7 \text { days } \\
& \text { 8-14 days }
\end{aligned}
$$

Unplanned face-to-face appointments I had difficulty being seen regarding my post-operative symptoms'
Table 3 Follow-up and post-operative complications (Continued)

\begin{tabular}{ll} 
Agree & $2(5 \%)$ \\
Neutral & $8(20 \%)$ \\
Disagree & $6(15 \%)$ \\
Strongly disagree & $20(50 \%)$ \\
\hline
\end{tabular}

patients following surgery. There is increasing evidence that many patients with COVID-19 are asymptomatic or have only mild symptoms, but are still able to transmit the virus to others [13]. Whether we are increasing their risk of asymptomatic infection following cataract surgery remains to be determined and requires further investigation.

Government reported data regarding the incidence of positive COVID-19 tests in the local government district of Ashford Hospital (Spelthorne) was 292 per 100,000 population at the start of the study (19 May 2020) and 457 per 100,000 population at the time of final data collection (17 September 2020). In comparison, the incidence at paper submission (14 Dec 2020) is now 2260 per 100,000 population [14].

We believe our study is robust due to our heterogenous group of patients, and thorough follow-up in which every patient or carer was contacted. Our cohort was comprised of people from BAME and nonBAME ethnicities, a broad age range and often with multiple comorbidities, including individuals potentially highly susceptible to COVID-19 infection. This is understandable as patients were not excluded from selection for cataract surgery on the basis of their health or comorbidities. One limitation is that we have not included data on patients who were offered cataract surgery but the patient declined to proceed, as this may reflect patients particularly at risk and hence unwilling to present to hospital except due to an emergency. Our hospital is also unusual in that we have no swab proven COVID-19

Table 4 Symptomatic COVID-19 infection rates post-operatively 30 day post-operative period

\begin{tabular}{ll}
\hline Shielding & Yes: $96(14.8 \%)$ \\
& No: $553(85.2 \%)$ \\
COVID-19 symptoms & Yes: 2 (0.3\%), both worsening dyspnoea \\
& No: 647 (99.7\%) \\
COVID-19 swab performed & Yes: $3(0.5 \%)$, all negative \\
& No: $646(99.5 \%)$ \\
Hospital admission & Yes: $3(0.5 \%)$ \\
& No: $646(99.5 \%)$ \\
ICU admission & No: $649(100 \%)$ \\
Mortality & Yes: $1(0.2 \%)$ \\
& No: $648(99.8 \%)$
\end{tabular}


Table 5 Patient experience

\begin{tabular}{ll}
\hline I was happy with my decision to proceed with cataract surgery during the \\
COVID-19 pandemic' \\
Strongly agree & $109(78.2 \%)$ \\
Agree & $24(3.7 \%)$ \\
Neutral & $6(0.9 \%)$ \\
Disagree & $2(0.3 \%)$ \\
Strongly disagree & $38(5.9)$ \\
'I was concerned I may have acquired COVID-19 infection due to attending \\
hospital for my cataract surgery' \\
Strongly agree & $50(7.7 \%)$ \\
Agree & $71(11.0 \%)$ \\
Neutral & $123(19.0 \%)$ \\
Disagree & $366(56.5 \%)$ \\
Strongly disagree & $1(0.2 \%)$ \\
I believe there were adequate infection control measures in hospital to \\
prevent transmission of COVID-19' \\
Strongly agree \\
Agree & $578(89.2 \%)$ \\
Neutral & $68(10.5 \%)$ \\
Disagree & $1(0.2 \%)$ \\
Strongly disagree & $0(0.0 \%$ \\
\end{tabular}

infected inpatients, potentially limiting applicability to hospitals with COVID-19 positive inpatients.

There was a restriction on anaesthetic service provision towards ophthalmology during the pandemic, due to redeployment of anaesthetists to other specialities, such as intensive care, and a higher demand in other ophthalmology sub-specialities necessitating emergency surgery under general anaesthesia, such as vitreoretinal and glaucoma surgery. There was a concerted effort by surgeons to perform cataract operations under local anaesthesia whenever possible. Hence the number of patients undergoing cataract surgery under general anaesthesia is particularly low in this study, with only three patients $(0.5 \%)$ in total, which is not reflective of surgical numbers prior to COVID-19.

The study also sheds light on a concern regarding masks potentially increasing the rate of post-operative endophthalmitis. It has been suggested that exhaled air jets are directed towards the eye by masks [15]. Our cohort had no cases of endophthalmitis (and none up to the date of submission of this paper) despite all patients required to wear surgical masks following completion of the operation. As mentioned, all patients were issued with a new sterile face mask at the entrance of the hospital, which was removed just before draping and replaced following completion of the operation.

Our intra-operative complication rate was substantially lower than the national average. For example, posterior capsular rupture rate was $1.14 \%$ in the most recent NOD audit [1], compared to $0.6 \%$ in our study. The 2 month hiatus from surgery had the potential to impact surgical skills $[16,17]$. However, we hypothesise that the reduced complications may be a result of the reduced time pressures the surgeons face, due to the staggered admission times and reduced numbers on the theatre lists, compared to pre-COVID-19 times. Alternatively, the limited general anaesthesia availability may have excluded particularly challenging cases. Conversely, surgeons may have operated on challenging cases under local anaesthesia which they may previously have operated on under general anaesthesia.

Similarly, our post-operative complication rate is also lower than expected [1]. It is likely that there has been under detection of post-operative complications, due to lack of routine face-to-face review and patients unwilling to present to hospital for further review. By collecting data at 30 day post-operatively, we will also miss later presenting complications, such as macular oedema.

One concern is a lack of clinic appointments, preventing patients from appropriately timed ophthalmic review in clinic, in response to post-operative symptoms. To counter this, we provided the patients with contact numbers within and outside of office hours, so they could speak directly with an ophthalmology-trained nurse or doctor relay their concerns. The vast majority of patients stated that they had no difficulty in arranging departmental review following the advent of their symptoms, adding support to routine telephone follow-up for uncomplicated cataract surgery. Longer term follow-up data is required to validate this model.

The recommended pre-operative isolation period changed during the study - from 14 days to 3 days, in keeping with NICE guidance [10]. Although not formally assessed, the majority of patients stated they complied with their quarantine period. The majority of patients in the study were instructed to isolate for 14 days, further studies are recommended to investigate the 3 day isolation period.

Lastly, with regards to subjective assessment, patients were in general very pleased with the service provided and happy they proceeded with cataract surgery. We appreciate this subjective assessment is prone to bias and hypothesise that patients may have underreported their concern for acquiring COVID-19 following the operation, in view of the fact they did not develop symptomatic infection. Patients concerned about acquiring COVID-19 infection would also have likely declined the offer of surgery. Hence we found a much lower proportion in comparison to pre-operative phone calls [18]. Similarly, we hypothesise that patients are more likely to retrospectively praise infection control measures, providing they were not knowingly infected. 
We believe our study will be applicable for other ophthalmic procedures. We recommend further study of COVID-19 infection rates following ophthalmic surgery, including investigating asymptomatic infection and multi-centre studies encompassing hospitals with differing demographics and COVID-19 prevalence, including patients with COVID-19 positive inpatients.

In summary, we demonstrate the safety of resuming cataract surgery in a COVID-19 free hospital, which may be a necessary solution, particularly relevant as we head towards another 'wave' [19].

\section{Acknowledgements}

None declared.

\section{Authors' contributions}

The contributors of this research article are the authors. FC and VG contributed to study concept, design and drafting of the manuscript. FC, PA, HN, TK, SA and AR contributed to data collection and analysis. All authors reviewed the manuscript. The author(s) read and approved the final manuscript.

\section{Funding}

The authors received no specific funding for this work.

\section{Availability of data and materials}

The datasets used and/or analysed during the current study are available from the corresponding author on reasonable request.

\section{Declarations}

\section{Ethics approval and consent to participate}

This study was approved by the Institutional Review Board of Ashford and St Peter's NHS Foundation Trust (TASCCOPHTH (2020-05)) and was performed in accordance with the ethical standards of the Declaration of Helsinki. The committee waived the need for written informed consent from the patients because the data was anonymised, however verbal consent was still obtained from all patients (or next-of-kin for the patient who passed away during the course of the study) by telephone follow-up.

\section{Consent for publication}

Not applicable.

\section{Competing interests}

The authors declare that they have no competing interests.

Received: 3 December 2020 Accepted: 5 April 2021

Published online: 09 April 2021

\section{References}

1. Royal College of Ophthalmologists. National Ophthalmology Database Audit. 2020. https://www.nodaudit.org.uk/u/docs/20/hasrgmurnv/NOD\%20A udit\%20Full\%20Annual\%20Report\%202020.pdf. Accessed 03 Dec 2020

2. World Health Organisation. Blindness and vision impairment. 2020. https:// www.who.int/news-room/fact-sheets/detail/blindness-and-visual-impa irment. Accessed 03 Dec 2020.

3. Royal National Institute of Blind People. The State of the Nation Eye Health 2017: a year in review. 2017. https://www.rnib.org.uk/sites/default/files/A PDF\%20The\%20State\%20of\%20the\%20Nation\%20Eye\%20Health\%202017\%2 0A\%20Year\%20in\%20Review.pdf. Accessed 03 Dec 2020.

4. World Health Organisation. Statement on the second meeting of the International Health Regulations (2005) Emergency Committee regarding the outbreak of novel coronavirus (2019-Nov). 2020. https://www.who.int/ news/item/30-01-2020-statement-on-the-second-meeting-of-the-interna tional-health-regulations-(2005)-emergency-committee-regarding-theoutbreak-of-novel-coronavirus-(2019-ncov). Accessed 03 Dec 2020

5. World Health Organisation. WHO Coronavirus Disease (COVID-19) Dashboard. 2020. https://covid19.who.int/. Accessed 03 Dec 2020.
6. Stevens S, Pritchard A. Next steps On NHS response to COVID-19. 2020. https://www.england.nhs.uk/coronavirus/wp-content/uploads/sites/52/2020/ 03/urgent-next-steps-on-nhs-response-to-covid-19-letter-simon-stevens.pdf. Accessed 03 Dec 2020.

7. Royal College of Ophthalmologists. RCOphth: management of ophthalmology services during the Covid pandemic. 2020. https://www. rcophth.ac.uk/wp-content/uploads/2020/03/RCOphth-Management-ofOphthalmology-Services-during-the-Covid-pandemic-280320.pdf. Accessed 03 Dec 2020.

8. Royal College of Ophthalmologists. Reopening and redeveloping ophthalmology services during Covid recovery. 2020. https://www. rcophth.ac.uk/wp-content/uploads/2020/04/Reopening-and-redevelopingophthalmology-services-during-Covid-recovery-Interim-guidance-1.pdf. Accessed 03 Dec 2020

9. Lamoureux EL, Fenwick E, Pesudovs K, Tan D. The impact of cataract surgery on quality of life. Curr Opin Ophthalmol. 2011;22(1):19-27. https:// doi.org/10.1097/ICU.0b013e3283414284.

10. The National Institute for Health and Care Excellence. COVID-19 rapid guideline: arranging planned care in hospitals and diagnostic services. 2020. https://www.nice.org.uk/guidance/ng179/resources/covid19-rapidguideline-arranging-planned-care-in-hospitals-and-diagnostic-services-pdf66141969613765. Accessed 03 Dec 2020.

11. Lin PF, Naveed H, Eleftheriadou M, Purbrick R, Zarei Ghanavati M, Liu C. Cataract service redesign in the post-COVID-19 era. Br J Ophthalmol. 2020 https://doi.org/10.1136/bjophthalmol-2020-316917.

12. Royal College of Ophthalmologists. Restarting and Redesigning of Cataract Pathways in response to the COVID 19 pandemic. 2020. https://www. rcophth.ac.uk/wp-content/uploads/2020/08/Resumption-of-CataractServices-COVID-August-2020-2.pdf. Accessed 03 Dec 2020.

13. He D, Zhao S, Lin Q, Zhuang Z, Cao P, Wang MH, et al. The relative transmissibility of asymptomatic COVID-19 infections among close contacts. Int J Infect Dis. 2020;94:145-7. https://doi.org/10.1016/j.ijid.2020.04.034.

14. United Kingdom Government. UK Coronavirus Data. 2020. https://corona virus.data.gov.uk/. Accessed 14 Dec 2020.

15. Hadayer A, Zahavi A, Livny E, Gal-Or O, Gershoni A, Mimouni K, et al. Patients wearing face masks during Intravitreal injections may be at a higher risk of endophthalmitis. Retina. 2020:40(9):1651-6. https://doi.org/10.1 097/IAE.00000000000002919.

16. General Medical Council. Skills fade: a review of the evidence that clinical and professional skills fade during time out of practice, and of how skills fade may be measured or remediated. 2014.

17. Nash E, Curry Jl, Blackburn SC. Returning to the theatre after an interval. R Coll Surg Engl: Bull. 2018;100(6):277-81. https://doi.org/10.1308/rcsbull.2018.277.

18. Naderi K, Maubon L, Jameel A, Patel DS, Gormley J, Shah V, et al. Attitudes to cataract surgery during the COVID-19 pandemic: a patient survey. Eye (Lond). 2020;34(12):2161-2. https://doi.org/10.1038/s41433-020-1112-9.

19. Looi MK. Covid-19: is a second wave hitting Europe? BMJ. 2020;371:m4113.

\section{Publisher's Note}

Springer Nature remains neutral with regard to jurisdictional claims in published maps and institutional affiliations.

Ready to submit your research? Choose BMC and benefit from:

- fast, convenient online submission

- thorough peer review by experienced researchers in your field

- rapid publication on acceptance

- support for research data, including large and complex data types

- gold Open Access which fosters wider collaboration and increased citations

- maximum visibility for your research: over $100 \mathrm{M}$ website views per year

At $\mathrm{BMC}$, research is always in progress.

Learn more biomedcentral.com/submission 